\title{
The Application of Situational Classroom on Electronic Information Teaching
}

\author{
XinXiao Qiao \\ Information School \\ QiLu University of Technology \\ JiNan, China \\ qxxyn@qlu.edu.cn
}

\begin{abstract}
The paper proposes a method to design situational classroom for electronic information courses. The difficulties of situational classroom are analyzed in first, then, the creation of situational classroom is described, which is explained with a detailed example. At last, several problems need to be noticed are introduced.
\end{abstract}

Keywords-situational classroom; situational games; electronic information; course

\section{INTRODUCTION}

Electronic information courses are obscure, whose logicalities are higher relatively. This makes their teaching be difficult. To teach electronic information course faces a great challenge. On one hand, how to firmly attract the attention of students on classroom teaching, how to transfer the knowledge effectively and train the ability of students have become a hotspot in university education. On the other hand, classroom game is an effective method to arouse the enthusiasm of students and attract the attention of students. Students can discuss, share the success and failure in games, master the obscure knowledge. This kind of teaching mode can deal with the arcane and difficult knowledge. However, how to design the classroom games that satisfy the requirement of electronic information is still a strict challenge.

In order to solve these problems in the teaching of electronic information courses, a method to design situational classroom game is proposed in the paper. An example is introduced to explain the detailed implementation process. The paper provides a method to design situational classroom game, which is suitable with electronic information for professional teachers.

With the development of information era, the technology of electronic information has become the forefront of the times. Its speed of knowledge updating and talent replacement is faster than other domains. The rapid development of science and technology leads to a huge demand for high level talents, which makes a higher request for university education. However, there is some prevailing phenomenon, such as arcane content, boring teaching, distracted listening, in the courses of electronic information. In this case, if teachers still teach the courses with traditional methods, it is easy to make students form the attitude of disgusted study, then gradually lose the interest to learn the difficult courses. Therefore, how to deal with the existing contents, find the right teaching method that is fit with modern college students and modern teaching features becomes an important research field.

Classroom games can guide the students to think actively and pay attention to the course, which can promote the enthusiasm and initiative of individual student. Classroom game is a kind of method to help students blend in classroom teaching and improve learning interest of students.

Classroom games usually are applied in foreign language, game development and a few courses of arts. The research on science and engineering education, especially on electronic information, is little. The problem has not been noticed by researchers. The main causes of the problem lie in the following aspects:

(1) Classroom games are thought to face on fixed courses, such as foreign language and game-related majors.

(2) Classroom games are thought to face on fixed student groups, such as students in primary and middle school and students on foreign language major.

(3) Due to traditional teaching patterns and thought, most of the science teachers of the university have used to teach with the question-and-answer method. Few teachers select the method of games.

(4) Because there are lots of knowledge points in science and engineering course, it is very difficult to design the curriculum content with the method of classroom games.

In order to teach on situational classroom, the theoretical knowledge must be converted to classroom games. This is a big challenge for teachers. In the paper, we take the network protocol analysis as an example to explain the method to design classroom games.

\section{CREATION OF CLASSROOM SITUATION}

Creation of situation is the most important content in instructional design, which requirements that we change traditional instructional design to the creation of learning environment. Aiming at the specific learning target, we should arrange leaning content into the real learning activities in classroom situation, let students obtain more effective learning by participating in real learning activities. In a simple word, to create classroom situation in instructional design is to arrange learning content in real or near-real activities supported by information technology. This would support teaching activities more effectively in school. 
Due to information instructional design due is closely combined with various information technology and information resources, this makes the creation of situation is more actual, and simple and efficient. In the proceeding of situation creation, most teachers utilize language, action and pictures to foil atmosphere. This can't provide the vivid and rich situation and make the learning become difficult. Information instructional design can provides text, graphics, audio, animation, video, et al. Rich interaction can create vivid, intuitive learning situation, which make teaching more intuitive and dynamic. Nonlinear of super text and super media links more meet human of thinking way, which can express the complexity of thinking and provide rich information source to help students analysis problem solution problem. This can cause students' interest of exploration and complete knowledge construction. In information instructional design, the creaton of situation can toggle students of chords, arouse interest, awaken the long-term memory of relevant knowledge, achieve the knowledge of "assimilation" and "adaptation."

\section{Method To CREATE ClASSROOM SituAtion}

The key of creation of classroom situation is to look for an appropriate of story or game. The knowledge points are thawed into story background, which are described with the way of story. But, it is different with general story, whose nature lies at situational classroom utilize the story as a carrier to provide a space of analogy imagine. With the description of situational story, students can find the relationship between knowledge points and phenomenon in daily life. This would attract students' attention and master the knowledge. General design situation of classroom games can be divided into the following steps: convert knowledge points to story situation; convert the story to detailed rules of games; combine and summary the knowledge points.

\section{A. Convertion of Knowledge Point}

The courses of electronic information are abstract and difficult to understand. Aiming at the characteristic, the paper proposes a method to integrate the knowledge points into specific story line of situational classroom games. However, how to design reasonable drama and link all of the knowledge points is the key of applying the method successfully. In the teaching, we can utilize analogies, personification, quasiphysical or figurative approach to convert the abstract concepts in computer science to a story, and try to find the correspondence among information curriculum theory and reallife examples, which helps students understand and master the knowledge. In the section, we would take "TCP/IP protocol” as an example to explain the detailed implementation of situational classroom.

The first step to design classroom games, teachers should find examples in daily life for knowledge points, and give students an intuitive feeling with analogies. For example, the process of sending data packets to the network with the TCP/IP protocol stack is similar with the process of sending letters at the post offices, as shown in Figure.1.

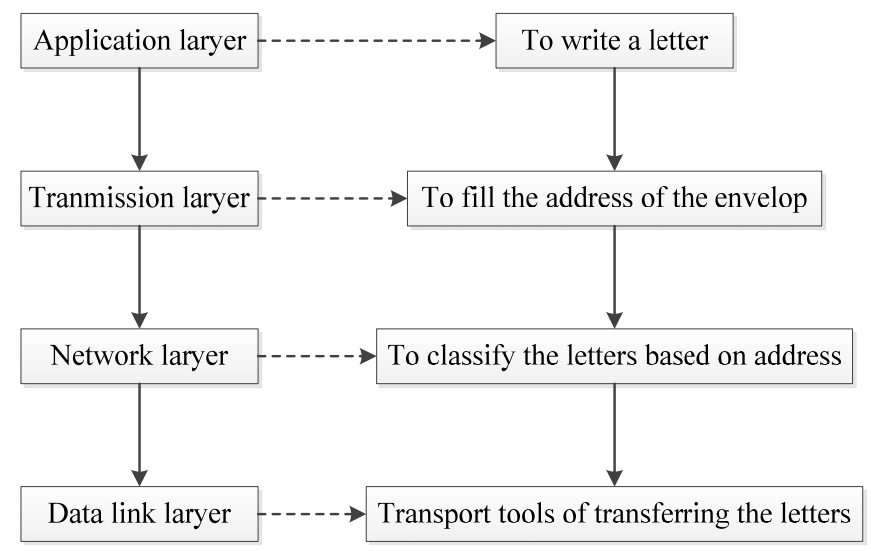

FIGURE I. CORRESPONDENCE BETWEEN TCP/IP PROTOCOL AND POSTING A LETTER

In the section of TCP/IP protocol, the application layer, transmission layer, network layer, data link layer and the basic concepts need to be taught. To illustrate the problem, we can link data packets to mail packets in real life. For example, if we would write a letter from Beijing to Guangzhou, the content of the letter is similar with application layer; to write the address on the envelope is similar with transmission layer. When the letter is prepared and sent to post office, the post office would classify the letters based on the target cities. The letters with the same target city would be sent out with the same label at the same time. But, the route from Beijing to Guangzhou would be adjusted based on the actual congesting situation. The process is similar to the network layer, which is fit with the character of data packets in network layer. At last, in the choice of transport means, a train, bus and plane is determined by the actual transport options, which is similar with data link layer. We can see a car as Ethernet, see a motorcycle as a token-ring network. And in many cases, Ethernet network is selected, but a token-ring network may be selected in some specific network.

\section{B. Design of Game Rules}

On the one hand, the design of classroom games should be associated with the knowledge points, which enhance students' knowledge by playing games. On the other hand, the games should have a certain interest and participatory, so as to arouse the enthusiasm of classroom climate and students. Because sending a packet from a source host to a destination host requires TCP/IP protocol stack to process layer by layer, so the process of sending packets can be divided into application layer, transport layer, network layer and data link layer, which can be respectively played by different students. When the content is written in application layer, the transmission layer should judge select TCP or UDP protocols, fill in packet header information. The data link layer selects the right MAC address. Whether the packet is filled in is the index to evaluate the transmission layer working correctly.

In the following section, the design of game rules is introduced.

(1)Rule 1: the selection of a transport mode and port information. 
A user is played by a student, that is, who plays the application layer. The student selects the destination and transmission mode of the letter. If he chooses the EMS Express, it means using the TCP protocol. Meanwhile, the student should fill in the appropriate TCP port field of the message head according to the destination address of the transport layer. Through this game section, students can fill in of the TCP packet header, and study the similarities and differences between TCP and UDP protocols.

(2) Rule 2: the selection of the right source IP address and destination IP address.

The IP packet header is filled in with corresponding address information by the student in charge of network layer. In the section, the presentation on IP address network-byte string conversion can be added. Through this section, students can have a more visual understanding to fill in the IP network address of the IP packet header and the string conversion.

(3) Rule 3: the selection of the right MAC address.

The Ethernet frame header is filled in according to the corresponding address information by the student in charge of data link layer. The application range of MAC address can be added in the section. The destination MAC address of the Ethernet frame header should be filled with the MAC address of the LAN Gateway. Through this section, students would have a more specific knowledge on Ethernet frame header format.

\section{Summary of Knowledge Points}

After introducing the game rules, teachers writes a complete structure of a data message on the blackboard, including application layer content, transmission layer header, IP package header and Ethernet frame headers. In classroom games, four students play the actor of application layer, transmission layer, network layer and data link layer. The student acting application layer is responsible for filling in right content at right position and decide to use TCP or UDP protocols. The student acting transmission layer is responsible for filling in port number in message package. The student acting network layer is responsible for filling in the header information of IP protocol, that is, IP address and the agreement type. If 4 byte of network address is used, we need to convert IP address formation. The student acting data link layer is responsible for filling in frame headers of Ethernet, that is, the corresponding MAC address.

For increasing interest and confrontation, students are divided into different groups, and timed the whole process and see which group completes the process fast and good. The teacher is responsible for controlling the whole progress of the game in the classroom and encourages students who don't participate in games correct the errors of participants. By participating in the game, students think, discuss and compare all of the knowledge points, enhance the understanding of this lesson.

After the games are over, the teacher reviews and summarizes the knowledge points timely, lead students to think by asking questions such as, how network address into a string, why the IP packet is a 4-byte IP address of the head instead of a string, why the TCP protocol can be reliable.

\section{SEveral Problems In Situaltional CalssRoom}

There are several problems that need to be paid attention to in the design of situational classroom, as follows:

\section{A. The Comprehensivation of Situational Classroom}

A good of situation should contain the content to promote students intelligence development, help students construct up good cognitive structure, and should contain the content to promote students' development of non-intelligence quality, emotional content and practice content. It should create a situation to promote students full development of psychological environment and groups environment and practice environment. The situational classroom should have rich thought connotation. The design of instructional situation should not just meet one aspect of requirements, which should can server for both emotional instructional service and cognitive, behavior instructional service, help students grasp teaching content.

\section{B. The Throughout of Situational Classroom}

Situational settings are often done before the teaching activities. This often leads some to mistake that the setting of a situation is done until the new courses using experiments and stories to arouse students' interest in learning, mobilize the enthusiasm of the students, leads to a new class. In fact, teaching situation sets are not the import new features in the traditional sense, which shouldn't just explain the situation before the new class. It should can stimulate, promote, strengthen, maintain and adjust the students' cognitive, emotional, and practical activities such as connect around, play a role in teaching process. To this end, the teaching can be set up in stages, gradually extended, in-depth, full and clear.

\section{The Developoment of Situational Classroom}

The development of situational classroom means that it should be inspiring, raise students' desire to continue learning, stimulate intellectual curiosity and increase the students' potential function. The set of teaching situation is not only to for student development of current level, but also to for students of "recently development district". It should be easy to propose current teaching to solution problem, and should contain some problem with current problem, and can raised further learning of problem, can caused students of active thinking, let students to aftertaste and divergent to reach a new level. The appropriate set of teaching situations is not only beneficial to the comprehensive use of knowledge, conducive to the consolidation and development of learning outcomes, and also helps students develop their individuality and talents, help the students to cooperate with each other.

\section{The Acceptability of Situational Classroom}

The set of situational classroom should consider whether students can accept the situation, should design an appropriate "path" and "step" to facilitate students to apply learned knowledge and skills, help students to transfer the situations to solve problems. As knowledge and skill transfer is always under the influence of individual and situational factors, so teachers must carefully choose and design. In such situations, the students enable to migrate to acquire knowledge and skills. 
Experiences and strategies can enable students to address specific problems and more colorful, and be ability to solve practical problems in the new situation and ability to gradually improve.

\section{SUMMARY}

A better situational classroom games should attract student to participate, mobilize the classroom atmosphere, to firmly attract students in the classroom. By constructing the reasonable story, the games will explain the knowledge points, help eliminate students' fear of abstract knowledge. After the game is over, teachers summary the knowledge in a timely manner, helps students to reflect on the whole game, in order to better grasp the knowledge points

\section{ACKNOWLEDGMENT}

This work is supported by two projects of Shandong Province Higher Educational Science and Technology Program (J12LN20 and J12LN09), China.

\section{REFERENCES}

[1] Yonghua Liu, "roles and methods of situaltional instuction," Instuction Reference of Junior High School, pp.9-10, 2009.

[2] Xiangmin Xu, Wei Gang, Zheng Li, Ruixiang Yin, "Exploration on training model of talents in research university," Research on Higher Engineering Education, pp.59-65, 2009.

[3] Geng Chen, Jiayuan Lu, "Study on the Mode of Talents Training in Information Technology of the Specialized University," Computer Education, pp. 4-7, 2011. 